\title{
Place of Tranexamic Acid and Fibrinogen Association in the Management of Severe Postpartum Haemorrhage
}

\author{
Raja Briki', Fahmi Ferhi², Ons Cherif ${ }^{*}$, Med Amine Saadi², Mouna Derouich ${ }^{1}$, Abdeljalil Khlifi' \\ Sassi Boughizane1, Khalil Tarmiz ${ }^{2}$
}

${ }^{1}$ Obstetrics and Gynecology Department, University Hospital Farhat Hached, Sousse, Tunisia

${ }^{2}$ Anesthesia and Resuscitation Department, University Hospital Farhat Hached, Sousse, Tunisia

Email: *onscherifb@gmail.com

How to cite this paper: Briki, R., Ferhi, F., Cherif, O., Saadi, M.A., Derouich, M., Khlifi, A., Boughizane, S. and Tarmiz, K. (2018) Place of Tranexamic Acid and Fibrinogen Association in the Management of Severe Postpartum Haemorrhage. Open Journal of Obstetrics and Gynecology, 8, 1040-1051. https://doi.org/10.4236/ojog.2018.811105

Received: August 15, 2018

Accepted: September 22, 2018

Published: September 25, 2018

Copyright (c) 2018 by authors and Scientific Research Publishing Inc. This work is licensed under the Creative Commons Attribution International License (CC BY 4.0).

http://creativecommons.org/licenses/by/4.0/

\begin{abstract}
Introduction: Severe postpartum hemorrhage (PPH) is the main cause of death in Tunisia. Its management is multidisciplinary and requires perfect knowledge of a regularly updated protocol and consistent with available resources. We propose an evaluation of the impact of different therapeutic attitudes, in particular the combination of tranexamic acid and fibrinogen concentrates in the management of this hemorrhage. Material and Methods: This was a retrospective, descriptive and analytical study, conducted in the departments of Gynecology-Obstetrics and Surgical Resuscitation anesthesia of the Farhat Hached University Hospital, Sousse, Tunisia. The study was conducted over six years (2009-2014), and included all parturients who were treated for severe PPH that occurred on a term greater than 24 weeks of amenorrhea. Patients were divided into two groups according to the study period: 1) Group 1 (G1): from 1 January 2009 to 31 December 2011, 2) Group 2 (G2): from January 1, 2012 to December 31, 2014, a group that benefited particularly from the combination of tranexamic acid and fibrinogen concentrates for the management of their PPH. Results: 166 patients were included: 57 in G1 and 109 in G2. The overall incidence of severe PPH was 3.15/1000 deliveries. We noted a significant decrease in the fall of hemoglobin in per and post haemorrhagic manifestations in favor of $G 2$ with a $p$ value of 0.003 and $\mathrm{p}=0.025$, respectively. The use of blood transfusion decreased significantly, in frequency and in number of packed red cells per patient, between the two groups; transfusion ratio was $1 / 1.7 / 1.5$ for G1, and 1/2/1.8 for G2. Fluid therapy, use of macromolecules and catecholamines were less important in G2. The use of tranexamic acid, fibrinogen and the association of both increased significantly between the two groups $\left(p<10^{-4}\right)$. Haemostasis hyste-
\end{abstract}


rectomies were less performed $\left(p<10^{-3}\right)$ in G2. Conclusion: The management of PPH has evolved over the years. The use of tranexamic acid in association with fibrinogen concentrates had proved his interest.

\section{Keywords}

Postpartum Haemorrhage, Tranexamic Acid, Fibrinogen, Management

\section{Introduction}

Postpartum haemorrhage ( $\mathrm{PPH}$ ) remains a public health problem in the world and in Tunisia. Its severity criteria are not consensual in the literature; classically, they associate: a blood loss greater than $1500 \mathrm{~mL}$, deglobulization of more than $4 \mathrm{~g} / \mathrm{dL}$ or a transfusion of at least 4 red blood cells [1]. This severity can also be appreciated on the basis of the only therapeutic consequences that it entails [2].

The management of PPH in particular severe is necessarily multidisciplinary, and requires the perfect knowledge of a regularly updated protocol, accessible at all times and consistent with the resources available in our context.

To study the evolution of our methods of management of severe $\mathrm{PPH}$, we conducted this retrospective study, and we set ourselves the main objective of evaluating the impact of different therapeutic attitudes on maternal morbidity and mortality, and particularly the contribution of the combination of tranexamic acid and human fibrinogen, by analyzing the approaches applied, both medical and obstetric, to severe HPP. Our research question was: is there a proven interest in associating tranexamic acid with fibrinogen concentrates in the management of severe $\mathrm{PPH}$ ?

\section{Materials and Methods}

This was a retrospective, descriptive and analytical study, conducted at the Farhat Hached University Hospital Center in Sousse, Tunisia, in the departments of Gynecology-Obstetrics and Surgical Resuscitation and Anesthesia. The study period was six years, from 01.01.2009 to 31.12.2014. Included were all women who gave birth, either vaginally or by caesarean section, in our maternity or who were transferred from another maternity and had severe PPH occurring over a period of more than 24 weeks of amenorrhea.

The criteria for the definition and severity of PPH were those of the National Institute of Health and Medical Research (INSERM) in the EPIMOMS (Epidemiology of Maternal Severely Morbid) and the High Authority of Health studies (HAS) [3] [4] having defined severe HPP by the presence of one or more of the following criteria:

- A blood loss $\geq 500 \mathrm{ml}$ if the birth was vaginal or $\geq 1000 \mathrm{ml}$ if it was done by cesarean section, 
- A cataclysmic haemorrhage,

- Hemodynamic instability and poor clinical tolerance,

- bleeding requiring the use of prostaglandins,

- A haemorrhage that required the transfusion of blood products,

- bleeding requiring haemostasis surgery,

- Hemorrhage requiring surveillance in the intensive care unit after delivery,

- Complicated hemorrhage of organ dysfunction,

- A bleeding that results in maternal death.

Exclusion criteria included patients with a history of constitutional or acquired hemostasis disorders, and those on anti-vitamin Ktreatment, heparin or platelet aggregation inhibitors.

To highlight the value of the tranexamic acid/fibrinogen association in reducing the morbidity and mortality involved by severe $\mathrm{PPH}$, our patients were divided into two groups:

- Group 1 (G1): from 1 January 2009 to 31 December 2011,

- Group 2 (G2): from 1 January 2012 to 31 December 2014, a period characterized by systematic use of tranexamic acid in combination with fibrinogen concentrates for the management of haemorrhage.

The two groups were compared against anthropometric data, pregnancy course, delivery course, risk factors for $\mathrm{PPH}$ occurrence, HPP etiology, $\mathrm{PPH}$ clinical-biological manifestations, medical treatments and surgical implemented, morbidities post HPP and secondary to its management and maternal mortality.

For statistical analysis, averages were compared using the student's t-test. The Mann-Whitney test was used when the validity conditions were not verified. Comparisons of qualitative variables between the two groups studied were made by Chi2 tests or exact Fisher tests, and comparisons of distributions of quantitative variables by analysis of variance (ANOVA). The significance threshold chosen for all the statistical analyzes was 0.05 .

The ethical approval of the committee of Farhat Hached University Hospital of Sousse,Tunisia was taken for this study.

\section{Results}

During the study period, the overall incidence of PPH between 2009 and 2014 was 3.15/1000 deliveries. It was 2.3/1000 deliveries between 2009 and 2011 and 3.8/1000 deliveries between 2012 and 2014 .

We excluded twenty-nine non-exploitable files (15.6\%). Ten patients were transferred to our center for additional management of severe $\mathrm{PPH}$ : five of these patients belonged to the first group and five to the second group. Figure 1 represents our study chart flow.

The two groups did not differ significantly from the anthropometric data and the theoretical risk factors for PPH: advanced maternal age (greater than 35 years), multiparity, previous cesarean section, gestational age at the time of delivery, main pregnancy pathologies and history of $\mathrm{PPH}$. The main characteristics of the study population are summarized in Table 1. 


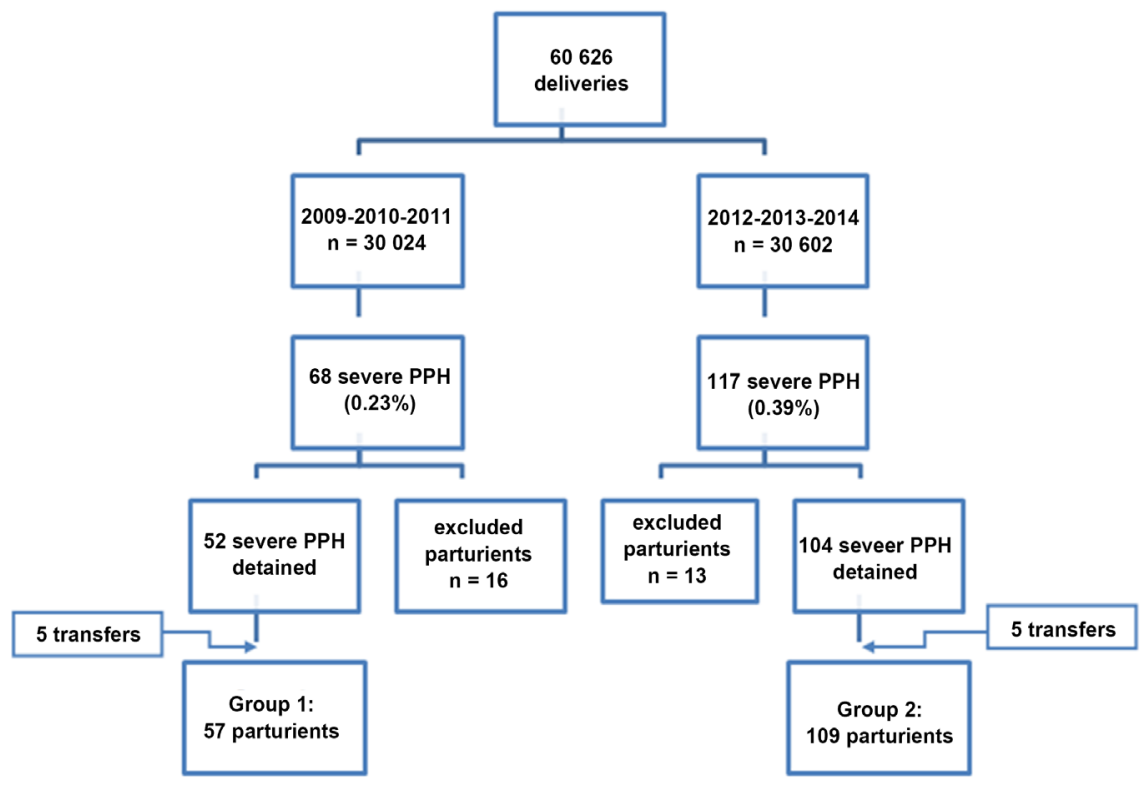

Figure 1. Profile of the study.

Table 1. General characteristics of the study population.

\begin{tabular}{|c|c|c|c|c|}
\hline & $\begin{array}{l}\text { Total population } \\
\qquad \mathrm{n}=166\end{array}$ & $\begin{array}{c}\text { Group } 1 \\
2009-2011 \\
\mathrm{n}=57\end{array}$ & $\begin{array}{c}\text { Group } 2 \\
2012-2014 \\
\mathrm{n}=109\end{array}$ & $p$ \\
\hline $\begin{array}{l}\text { Mean age } \pm \text { standard } \\
\text { deviation [extremes] }\end{array}$ & $\begin{array}{c}32 \pm 5.4 \text { ans } \\
{[18-45]}\end{array}$ & $\begin{array}{c}31.82 \pm 5.36 \text { ans } \\
{[18-43]}\end{array}$ & $\begin{array}{c}32.02 \pm 5.49 \text { ans } \\
{[19-45]}\end{array}$ & 0.175 \\
\hline Age $>35$ years, $\mathrm{n}(\%)$ & $42(25.3)$ & $15(26.2)$ & $27(24.7)$ & 0.127 \\
\hline $\begin{array}{c}\text { Mean gestity } \pm \text { standard } \\
\text { deviation }\end{array}$ & $2.54 \pm 1.51$ & $2.75 \pm 1.45$ & $2.43 \pm 1.58$ & 0.279 \\
\hline $\begin{array}{c}\text { Mean parity } \pm \text { standard } \\
\text { deviation }\end{array}$ & $1.42 \pm 1.37$ & $1.6 \pm 1.49$ & $1.39 \pm 1.26$ & 0.548 \\
\hline Multiparous, n (\%) & $99(60.1)$ & $28(49.2)$ & $71(65)$ & 0.141 \\
\hline Single uterine scar, $\mathrm{n}(\%)$ & $9(5.4)$ & $3(5.2)$ & $6(5.5)$ & 0.291 \\
\hline Multiple uterine scars, n (\%) & $4(2.4)$ & $1(1.8)$ & $3(2.8)$ & 0.322 \\
\hline PPH history, $\mathrm{n}(\%)$ & $5(3)$ & $3(5.3)$ & $2(1.8)$ & 0.22 \\
\hline $\begin{array}{c}\text { Mean gestational age at } \\
\text { delivery } \pm \text { standard } \\
\text { deviation [extremes] }\end{array}$ & $\begin{array}{c}38.6 \pm 1.64 \\
{[30-42]}\end{array}$ & $\begin{array}{c}38.3 \pm 1.57 \\
{[30-41]}\end{array}$ & $\begin{array}{c}38.9 \pm 1.62 \\
{[32-42]}\end{array}$ & 0.298 \\
\hline \multicolumn{5}{|l|}{ Associated pathologies: } \\
\hline $\begin{array}{l}\text { - Preeclampsia/Pregnancy } \\
\text { hypertension }\end{array}$ & 10 & 1 & 9 & 0.09 \\
\hline - Gestational Diabetes & 5 & 1 & 4 & 0.493 \\
\hline - Macrosomia & 11 & 3 & 8 & 0.105 \\
\hline - Hydramnios & 6 & 2 & 4 & 0.398 \\
\hline
\end{tabular}

Of the preeclamptic patients, none had HELLP syndrome or acute hepatic steatosis.

Regarding the course of labor and delivery, the overall rate of caesarean section was $54.2 \%$. 
There was no significant difference between our groups according to the mode of delivery $(p=0.975)$. For patients who gave birth vaginally $(45.60 \%$ in G1, 45.90\% in G2), there was no significant difference regarding the use of induction and work direction, the use of instrumental help (forceps) and practice an episiotomy. The rate of emergency caesareans in the general population was 65.5\%: $67.7 \%$ for $\mathrm{G} 1$ and $64.4 \%$ for G2, with $p=0.591$.

Abnormal bleeding and uterine atony were the most common obstetric manifestations. This atony was significantly greater in G2 (40.4\% for G1 and 63.3\% for $\mathrm{G} 2, p=0.05)$. Haemodynamic alterations were less frequent with no difference between the 2 groups and whatever the mode of delivery.

Concerning the etiologies of hemorrhage, primary atony was the first cause retained (90 cases, 54.2\%). It was secondary in 26 cases (placenta accreta in 3 cases, uterine retention in 2 cases, uterine rupture in 1 case, tear of the cervix and/or vagina in 18 cases and wide episiotomy in 2 cases). No significant differences were noted between the two groups regarding the etiologies of $\mathrm{PPH}$.

Management's delay of PPH was less than $30 \mathrm{~min}$ for $40 \%$ of patients with no significant difference between the 2 groups $(p=0.423)$. The averages of this delay were $30.42 \pm 47 \mathrm{~min}$ and $40.68 \pm 87 \mathrm{~min}$ respectively in G1 and G2.

The conditioning was according to the norms for all patients. Invasive monitoring of blood pressure was performed in 19 patients of G1 and 30 of G2, and central venous cath in 10 patients of G1 and 13 of G2.

For anesthetic technique, general anesthesia was $66.9 \%$ in choice. A conversion of a regional anesthesia was noted in $25.9 \%$ of cases, and the two groups were statistically comparable regarding the choice of anesthetic technique.

Exclusive use of crystalloids for vascular filling was significantly greater in group $2(p=0.031)$. The frequency of use of colloids was three times lower in this group $(p=0.05)$, and the average filling volumes administered to G2 patients were significantly lower $(p=0.04)$.

Also, the use of labile blood products was significantly lower in G2 ( $p=$ 0.002). The parturient rate transfused was $93 \%$ in G1 and $72.5 \%$ in G2. Therefore, we noted a decrease over the years in the number of packed red blood cells (RBC) transfused with a significant difference between the year 2014/2013 ( $p=$ $0.003)$ versus the year $2009(p=0.008)$. There was no significant difference in platelet pellets $(\mathrm{PP})$ transfusion $(p=0.198)$ or fresh frozen plasma (FFP) transfusion $(p=0.323)$ and the number of FFP transfused annually remained relatively stable. Thus, the transfusion ratio (RBC/PP/FFP) was $1 / 1.7 / 1.5$ for $\mathrm{G} 1$ and $1 / 2 / 1.8$ for $\mathrm{G} 2$.

Regarding the anti-fibronolytique treatment and fibrinogen, the use of the association of tranexamic acid and fibrinogen was significantly higher in G2 $(p<$ $10^{-4}$ ) (Figure 2). The frequency of their use together increased relative to the use of either separately (Figure 2). The average dose of tranexamic acid was $1.98 \mathrm{~g} \pm$ 0.55 , and $2.25 \mathrm{~g} \pm 0.71$ for fibrinogen. In $95 \%$ of the patients, the doses used for one or other of these molecules were 2 grams. 


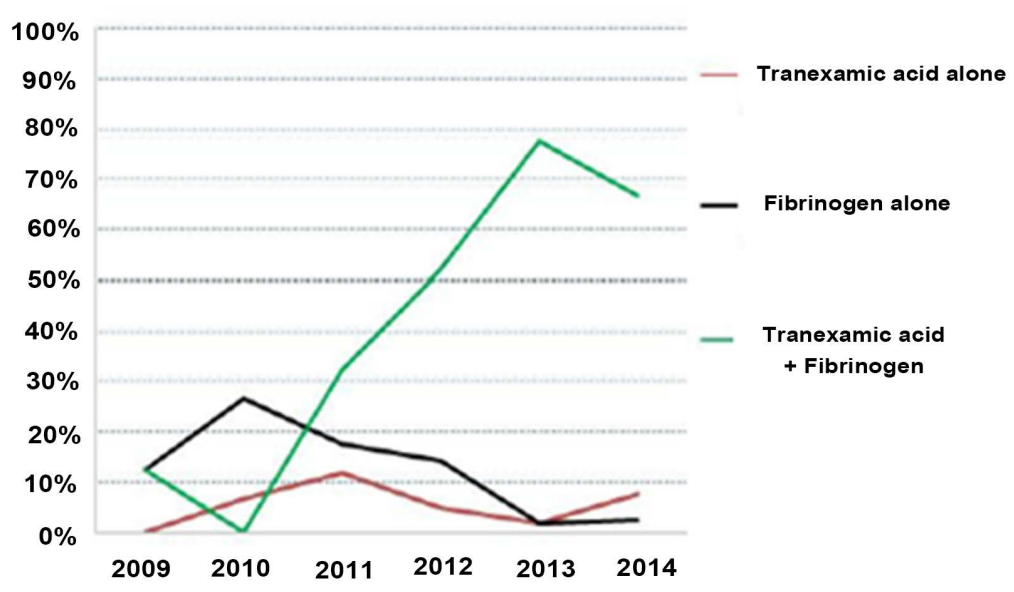

Figure 2. Evolution of the use of tranexamic acid and fibrinogen.

Oxytocin was used exclusively in $33.3 \%$ patients of G1 and $26.6 \%$ of G2. Maximum doses used were 40 IU with a median of 30 IU. Sulprostone was used in $66.7 \%$ and $73.4 \%$ respectively in $\mathrm{G} 1$ and $\mathrm{G} 2$.

Catecholamines were used in $17.5 \%$ for G1 and $11.9 \%$ for G2. The doses were significantly higher in G1 with an average of $2.5 \mathrm{mg} \pm 0.25 \mathrm{in}$ G1 and $1 \mathrm{mg} \pm$ 0.14 in G2 $(p=0.049)$.

For obstetric management, the surgical procedures used were statistically comparable between the 2 groups. The use of hysterectomy for haemostasis was significantly less important in the 2 nd group (23 cases or $21.1 \%$ in G2 versus 28 cases or $49.1 \%$ in $\mathrm{G} 1, p<10^{-3}$.

About evaluation of blood loss, the mean values of hemoglobin at nadir $(6.23 \pm$ $1.56 \mathrm{~g} / \mathrm{dl}$ for $\mathrm{G} 1,7.31 \pm 2.09$ for $\mathrm{G} 2, p=0.003$ ), the lowest hemoglobin values, in per and post hemorrhagic manifestations were significantly lower in the 1 st group. Mean deglobulization was $3.7 \pm 1.7 \mathrm{~g} / \mathrm{dl}$ in $\mathrm{G} 1$ and $2.8 \pm 1.9 \mathrm{~g} / \mathrm{dl}$ in G2, with a significant difference between the two groups $(p=0.012)$.

So, we noted a decrease in the use of blood transfusion and hemostasis hysterectomy with increasing use of antifibrinolytics and fibrinogen simultaneously (tranexamic acid + fibrinogen association) (Figure 3).

Regarding the consequent morbidity, $31.6 \%$ of G1 patients had one or more complications versus $19.3 \%$ of G2. A secondary hemodynamic failure to the $\mathrm{PPH}$ and requiring recourse to catecholamines beyond 6 hours after surgery was observed in $19.3 \%$ of $\mathrm{G} 1$ patients versus $1.8 \%$ of $\mathrm{G} 2(p=0.027)$. Mechanical ventilation was required in $15.8 \%$ of G1 patients and $11 \%$ of G2. The duration of hospitalization in intensive care unit was 2.7 days on average with a maximum of 23 days. There was no significant difference between the two groups in terms of length of hospital stay $(p=0.121)$. An increase in blood creatinine was noted by $3.5 \%$ of G1 patients and $5.5 \%$ of G2. This was not case of extracorporeal treatment.

Complications related to transfusion were $7 \%$ in G1 versus $1.8 \%$ in G2 and TRALI type in 4 patients (including 3 in G1), an urticaria in one case of G2 and 


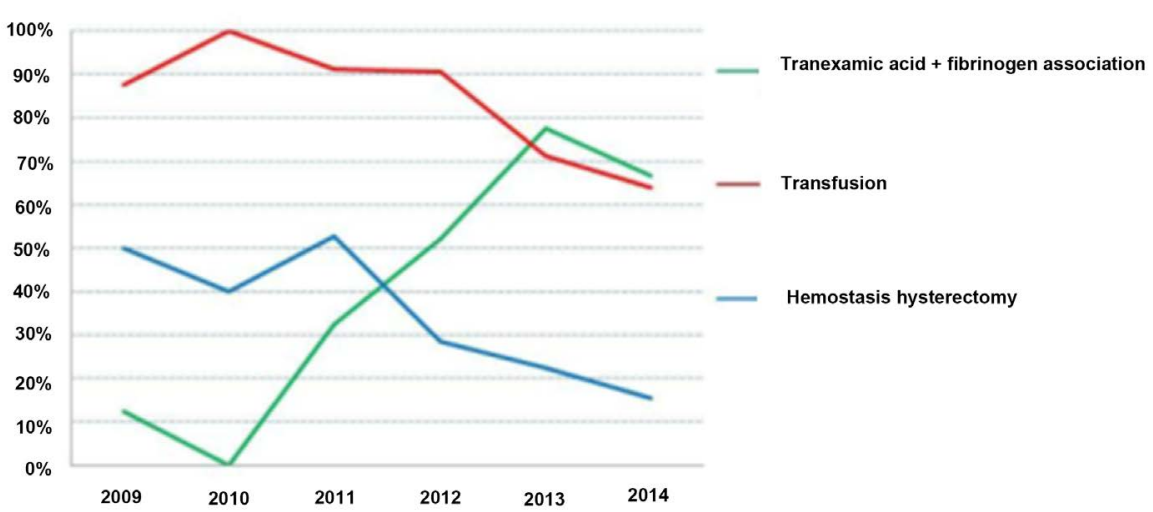

Figure 3. Evolution of different therapeutic methods based on years of study.

biological hypocalcemia in one case of G1. Sheehan's syndrome manifested in 3 patients, one of G1 and 2 of G2.

About mortality, we recorded five deaths, including three in G1 and two in G2 without significant difference $(p=0.22)$. Four of the deceased were patients who were transferred from peripheral maternity, and whose cause of death was a multi-visceral failure syndrome secondary to hemorrhagic shock. The fifth death was due to a septic shock occurring on the 21 st day of hospitalization.

\section{Discussion}

Postpartum hemorrhage (PPH) severity criteria vary in the literature: blood loss greater than $1500 \mathrm{ml}$, fall in hemoglobin of more than $4 \mathrm{~g} / \mathrm{dl}$ or need to transfuse [5], hemorrhagic shock, use of invasive techniques, need for transfer to the intensive care unit, and finally maternal death [6]. All parturients of our series had presented at least one criterion of severity among the evoked ones.

The study we conducted concluded that the mean incidence of severe PPH was $3.15 / 1000$ deliveries, and our analysis showed an increase in the incidence of severe PPH from 2.3/1000 deliveries (2009-2011) to 3.8/1000 deliveries (2012-2014). Several studies have reported a recent increase in the incidence of PPH [7] [8].

Our study showed no significant differences between the two groups in terms of PPH risk factors. However, there is a tendency for recrudescence of placental insertion abnormalities in recent years. For cesarean section, its urgency, the need for general anesthesia and a vertical incision are recognized as risk factors for PPH [9] [10]. The use of oxytocin for induction and/or management of obstetric labor could also be provider of uterine inertia and PPH [11] [12].

In accordance with the literature [13] [14], uterine atony, whether primary or secondary, was the first etiology of severe PPH in our series (70\% of cases).

The management of severe $\mathrm{PPH}$ is multidisciplinary involving obstetrician, anesthesiologist, radiologist and blood-biologist. It must be fast, aggressive and organized.

Our analysis places special emphasis on the increased use of human fibrinogen and tranexamic acid and particularly together in association. Indeed, a severe 
PPH is often associated with coagulopathy by a triple mechanism: loss of coagulant proteins by bleeding, their consumption and dilution by vascular filling. Fibrinogen is the first factor of coagulation to subside during hemorrhagic shock [15]. Low fibrinemia at the beginning of $\mathrm{PPH}$ has been shown to be a strong predictor of its progression to severity. Charbit et al. [16] have shown in a prospective and multicentric study of 128 parturients that a cut-off rate of $4 \mathrm{~g} / \mathrm{L}$ was $74 \%$ sensitive and $65 \%$ specific. Thus, a fibrinemia rate $>4 \mathrm{~g} / \mathrm{L}$ has a negative predictive value of progression to severity at $79 \%$ and a rate $<2 \mathrm{~g} / \mathrm{L}$ has a positive predictive value at $100 \%$. They also demonstrated that only fibrinemia was a predictor independent of severity [16]. These same results were confirmed by Cortet et al. [17] in a prospective and multicentric study including 738 parturient patients suffering from PPH after vaginal delivery. They found that a fibrinogen level between $2-3 \mathrm{~g} / \mathrm{L}$ increased the risk of severity by $2(\mathrm{OR}=1.9)$ and that a rate $<2 \mathrm{~g} / \mathrm{L}$ by $12(\mathrm{OR}=11.99)$ [17].

Currently, no obstetric study can determine the amount of fibrinogen to administer. The US and UK guidelines recommend the administration of human fibrinogen from a threshold of $1 \mathrm{~g} / \mathrm{L}$ of serum fibrin [18] [19]. The European recommendations [20] initially proposed to prescribe 3 to 4 grams then to re-administer according to the biological evolution.

Our study shows a significant difference in favor of the 2nd group as regards the administration of human fibrinogen $\left(p<10^{-3}\right)$ with a mean dose per patient of $2.25 \mathrm{~g}$ and extremes ranging from 1 to $5 \mathrm{~g}$. Our average doses were slightly lower than the recommendations but no study can guide us on the optimal dose.

Tranexamic acid is an antifibrinolytic agent. It is a synthetic analogue of lysine, a competitive inhibitor of plasmin and plasminogen, and thus inhibits fibrinolysis and reduces bleeding [21]. The value of this product has been proven outside the obstetrical area [22] [23] [24], but its use has also been proven in obstetrics. It has been used both to prevent the occurrence of PPH during delivery and also for treatment [21] [25]-[32]. Our study shows that we are using this molecule more and more with a significant difference between the two groups $\left(p<10^{-6}\right)$. Doses used were close to $2 \mathrm{~g}$ per patient: $1 \mathrm{~g}$ over 10 minutes and $1 \mathrm{~g}$ over 6 hours. Our extreme doses were 1 to $4 \mathrm{~g}$. No recommendation is yet made as to the modality and the dose of the administration of tranexamic acid. The use of tranexamic acid in association with fibrinogen concentrates appears to be interesting. No study has sought to demonstrate the potential benefit of simultaneous administration of these two molecules. In our series, the use of this association is significantly greater in the 2 nd group $\left(p<10^{-4}\right)$. The frequency of use of this association increases to the employment profile of either one separately.

For the surgical management, a net decrease in hemostasis hysterectomy is noteworthy. Hysterectomy indications for haemostasis include failure of conservative treatment, major uterine disruption (irreparable uterine rupture) and extensive placenta accreta. Our series is comparable to international findings with a significant reduction between the two groups $(49.1 \%$ versus $21.1 \%, p<$ 
$10^{-3}$ ). This could have a multifactorial explanation: a better knowledge of the pathology and its imperatives, a better management by the obstetrical team, a more intensive and early resuscitation associated with the significantly increased addition of human fibrinogen and tranexamic acid [33].

\section{Limitations of the Study}

Our study remains a retrospective study. We tried to be the most exhaustive possible in the selection of files by crossing several sources.

Unfortunately, we have not been able to analyze the deadlines support for severe $\mathrm{PPH}$ in almost $45 \%$ of cases, while the analysis of the speed of introduction of the different treatments remains paramount to evaluate the correct application of therapeutic algorithms.

The main point of clinical appeal was the finding of bleeding unnatural. This remains the domain of visual estimation and approximation because we do not have bags of collections. These bags have become systematic.

We hypothesize that the treatments reduced incidence of severe PPH. It is possible, however, that 2 nd population group should be better taken care of initially, or by greater and faster presence of resuscitating anesthetist doctors and gynecologists obstetricians, or by other factors without us being able explain.

\section{Conclusion}

Severe PPH remains a real public health problem in Tunisia and in the world. Its management has evolved over the years. Better management of fluid therapy, the addition of fibrinogen and tranexamic acid and changes in blood transfusion policy allowed a saving blood products and a reduction in hemostasis hysterectomies. The use of tranexamic acid in association with fibrinogen concentrates had proved his interest.

\section{Conflicts of Interest}

The authors declare no conflicts of interest regarding the publication of this paper.

\section{References}

[1] Bose, P., Regan, F. and Paterson-Brown, S. (2006) Improving the Accuracy of Estimated Blood Loss at Obstetric Haemorrhage Using Clinical Reconstructions. BJOG, 113, 919-924. https://doi.org/10.1111/j.1471-0528.2006.01018.x

[2] American College of Obstetricians and Gynecologists (2006) ACOG Practice Bulletin: Clinical Management Guidelines for Obstetrician-Gynecologists Number 76, October 2006: Postpartum Haemorrhage. Obstetrics and Gynecology, 108, 1039-1047.

[3] EPIMOMS. Définition de la morbidité maternelle sévère. https://www.prevention-medicale.org/Actualites-et-revues-de-presse/Toutes-les-act ualites/Sage-femme/epidemiologie-morbidite-maternelle

[4] HAS. Recommandations pour la pratique clinique. Hémorragies du post-partum immédiat.

http://www.hassante.fr/portail/upload/docs/application/pdf/HPP_recos.pdf 
[5] Waterstone, M., Bewley, S. and Wolfe, C. (2001) Incidence and Predictors of Severe Obstetric Morbidity: Case-Control Study. BMJ, 322, 1089-1093. https://doi.org/10.1136/bmj.322.7294.1089

[6] Deneux-Tharaux, C., Dupont, C., Colin, C., Rabilloud, M., Touzet, S., Lansac, J., et al. (2010) Multifaceted Intervention to Decrease the Rate of Severe Postpartum Haemorrhage: The PITHAGORE6 Cluster-Randomised Controlled Trial. BJOG, 117, 1278-1287. https://doi.org/10.1111/j.1471-0528.2010.02648.x

[7] Callaghan, W.M., Kuklina, E.V. and Berg, C.J. (2010) Trends in Postpartum Hemorrhage: United States, 1994-2006. American Journal of Obstetrics \& Gynecology, 202, 353.e1-353.e6. https://doi.org/10.1016/j.ajog.2010.01.011

[8] Cameron, C.A., Roberts, C.L., Olive, E.C., Ford, J.B. and Fischer, W.E. (2006) Trends in Postpartum Haemorrhage. Australian and New Zealand Journal of Public Health, 30, 151-156. https://doi.org/10.1111/j.1467-842X.2006.tb00109.x

[9] Gilstrap, L.C.I., Hauth, J.C.M., Hankins, G.D.V.M. and Patterson, A.R.M. (1987) Effect of Type of Anesthesia on Blood Loss at Cesarean Section. Obstetrics \& Gynecology, 69, 328-332.

[10] Al-Zirqi, I., Vangen, S., Forsen, L. and Stray-Pedersen, B. (2009) Effects of Onset of Labor and Mode of Delivery on Severe Postpartum Hemorrhage. American Journal of Obstetrics \& Gynecology, 201, 273.e1-273.e9.

https://doi.org/10.1016/j.ajog.2009.06.007

[11] Belghiti, J., Kayem, G., Dupont, C., Rudigoz, R.C., Bouvier-Colle, M.H. and Deneux-Tharaux, C. (2011) Oxytocin during Labour and Risk of Severe Postpartum Haemorrhage: A Population-Based, Cohort-Nested Case-Control Study. BMJ Open, 1, e000514. https://doi.org/10.1136/bmjopen-2011-000514

[12] Grotegut, C.A., Paglia, M.J., Johnson, L.N., Thames, B. and James, A.H. (2011) Oxytocin Exposure during Labor among Women with Postpartum Hemorrhage Secondary to Uterine Atony. American Journal of Obstetrics and Gynecology, 204, 56.e1-56.e6. https://doi.org/10.1016/j.ajog.2010.08.023

[13] Dupont, C., Rudigoz, R.C., Cortet, M., et al. (2014) Frequency, Causes and Risk Factors of Postpartum Haemorrhage: A Population-Based Study in 106 French Maternity Units. Journal de Gynécologie Obstétrique et Biologie de la Reproduction (Paris), 43, 244-253. https://doi.org/10.1016/j.jgyn.2013.05.003

[14] Alamia Jr., V. and Meyer, B.A. (1999) Peripartum Hemorrhage. Obstetrics and Gynecology Clinics of North America, 26, 385-398. https://doi.org/10.1016/S0889-8545(05)70081-4

[15] Hiippala, S.T., Myllyla, G.J. and Vahtera, E.M. (1995) Hemostatic Factors and Replacement of Major Blood Loss With Plasma-Poor Red Cell Concentrates. Anesthesia and Analgesia, 81, 360-365.

[16] Charbit, B., Mandelbrot, L., Samain, E., Baron, G., Haddaoui, B., Keita, H., et al. (2007) The Decrease of Fibrinogen Is an Early Predictor of the Severity of Postpartum Hemorrhage. Journal of Thrombosis and Haemostasis, 5, 266-273. https://doi.org/10.1111/j.1538-7836.2007.02297.x

[17] Cortet, M., Deneux-Tharaux, C., Dupont, C., Colin, C., Rudigoz, R., Bouvier-Colle, Mh., et al. (2012) Association between Fibrinogen Level and Severity of Postpartum Haemorrhage: Secondary Analysis of a Prospective Trial. British Journal of Anaesthesia, 108, 984-989. https://doi.org/10.1093/bja/aes096

[18] Association of Anaesthetists of Great Britain and Ireland, Thomas, D., Wee, M., Clyburn, P., et al. (2010) Blood Transfusion and the Anaesthetist: Management of Massive Haemorrhage. Anaesthesia, 65, 1153-1161. 
https://doi.org/10.1111/j.1365-2044.2010.06538.x

[19] UK Blood Transfusion \& Tissue Transplantation Services (2007) The Handbook for Transfusion Medicine.

https://www.transfusionguidelines.org/transfusion-handbook

[20] Rossaint, R., Bouillon, B., Cerny, V., Coats, T.J., Duranteau, J., Fernandez Mondejar, E., et al. (2010) Management of Bleeding Following Major Trauma: An Updated European Guideline. Critical Care, 14, R52. https://doi.org/10.1186/cc8943

[21] Novikova, N. and Hofmeyr, G.J. (2010) Tranexamic Acid for Preventing Postpartum Haemorrhage. Cochrane Database of Systematic Reviews, 7, CD007872.

[22] Henry, D.A., Carless, P.A., Moxey, A.J., et al. (2007) Anti-Fibrinolytic Use for Minimising Perioperative Allogeneic Blood Transfusion. Cochrane Database of Systematic Reviews, 3, CD001886.

[23] Ker, K., Edwards, P., Perel, P., Shakur, H. and Roberts, I. (2012) Effect of Tranexamic Acid on Surgical Bleeding: Systematic Review and Cumulative Meta-Analysis. BMJ, 344, e3054.

[24] CRASH-2 Trial Collaborators (2010) Effects of Tranexamic Acid on Death, Vascular Occlusive Events, and Blood Transfusion in Trauma Patients with Significant Haemorrhage (CRASH-2): A Randomised, Placebo-Controlled Trial. The Lancet, 376, 23-32. https://doi.org/10.1016/S0140-6736(10)60835-5

[25] Yang, H., Zheng, S. and Shi, C. (2001) Clinical Study on the Efficacy of Tranexamic Acid in Reducing Postpartum Blood Lose: A Randomized, Comparative, Multicenter Trial. Chinese Journal of Obstetrics and Gynecology, 36, 590-592.

[26] Gungorduk, K., Asıcıoğlu, O., Yıldırım, G., Ark, C., Tekirdağ, A.İ. and Besımoglu, B. (2013) Can Intravenous Injection of Tranexamic Acid Be Used in Routine Practice with Active Management of the Third Stage of Labor in Vaginal Delivery? A Randomized Controlled Study. American Journal of Perinatology, 30, 407-413.

[27] Gai, M.Y., Wu, L.F., Su, Q.F. and Tatsumoto, K. (2004) Clinical Observation of Blood Loss Reduced by Tranexamic Acid during and after Caesarian Section: A Multi-Center, Randomized Trial. European Journal of Obstetrics \& Gynecology and Reproductive Biology, 112, 154-157. https://doi.org/10.1016/S0301-2115(03)00287-2

[28] Gungorduk, K., Yildirim, G., Asicioglu, O., Gungorduk, O.C., Sudolmus, S. and Ark, C. (2011) Efficacy of Intravenous Tranexamic Acid in Reducing Blood Loss after Elective Cesarean Section: A Prospective, Randomized, Double-Blind, Placebo-Controlled Study. American Journal of Perinatology, 28, 233-240. https://doi.org/10.1055/s-0030-1268238

[29] Shahid, A. and Khan, A. (2013) Tranexamic Acid in Decreasing Blood Loss during and after Caesarean Section. Journal of the College of Physicians and Surgeons Pakistan, 23, 459-462.

[30] Xu, J., Gao, W. and Ju, Y. (2013) Tranexamic Acid for the Prevention of Postpartum Hemorrhage after Cesarean Section: A Double-Blind Randomization Trial. Archives of Gynecology and Obstetrics, 287, 463-468. https://doi.org/10.1007/s00404-012-2593-y

[31] Shakur, H., Elbourne, D., Gulmezoglu, M., Alfirevic, Z., Ronsmans, C., Allen, E., et al. (2010) The WOMAN Trial (World Maternal Antifibrinolytic Trial): Tranexamic Acid for the Treatment of Postpartum Haemorrhage: An International Randomised, Double Blind Placebo Controlled Trial. Trials, 11, 40. https://doi.org/10.1186/1745-6215-11-40 
[32] Ducloy-Bouthors, A.S., Jude, B., Duhamel, A., Broisin, F., Huissoud, C., et al. (2011) High Dose Tranexamic Acid Reduces Blood Loss in Post Partum Hemorrhage. Critical Care, 15, R117. https://doi.org/10.1186/cc10143

[33] Salvat, J., Schmidt, M.H., Guilbert, M. and Martino, A. (2002) Vascular Ligation for Severe Obstetrical Hemorrhage: Review of the Literature. Journal de Gynecologie, Obstetrique et Biologie de la Reproduction, 31, 629-639. 